\title{
Metagenomics and physico-chemical analysis of the active mesophilic and mature phases of a fast composting system
}

\author{
Madhavi Navnit Londhe ${ }^{1}$, Sunil Kumar Sethy ${ }^{1}$, Suresh K. Shettigar ${ }^{2}$ and \\ S. B. Ghosh ${ }^{1, *}$ \\ ${ }^{1}$ Nuclear Agriculture and Biotechnology Division, and \\ ${ }^{2}$ Medical Division, Bhabha Atomic Research Centre, Trombay, Mumbai 400 085, India
}

Using different combinations of aerobic predigester microflora from different biphasic biogas plants, an optimum compost microflora was obtained. This microflora can fully degrade organic kitchen waste into mature compost in $96 \mathrm{~h}$. To further understand the dynamics of the degradation, several physicochemical properties, namely $\mathrm{pH}$, temperature, $\mathrm{C} / \mathrm{N}$ ratio and germination index were studied temporally. It was found that $24-48 \mathrm{~h}$ is the microbially most active phase, whereas at $96 \mathrm{~h}$ the organic matter is fully degraded. The present microflora did not produce any foul smell during progression of the composting process. To understand the microbial population and its dynamics, V3-V4 region-based $16 \mathrm{~S}$ rRNA metagenomic analysis was done for the microbial population at 24 and $72 \mathrm{~h}$ post organic waste addition. It was found that several unique organisms which were never reported in the context of composting are present in this consortium and relative abundance of several organisms changed during the process from 24 to $72 \mathrm{~h}$.

Keywords: Active phase, compositing process, microflora, microbial dynamics.

MUNICIPAL solid waste is a highly heterogeneous material of diverse origin. According to the World Health Organization, solid waste can be defined as useless, unwanted material arising from different human activities, including agriculture, industry, trade and sundry day-today activities ${ }^{1}$. Solid waste has become a serious environmental problem and one of the major growing concerns for urban areas all over the world. The waste processing has been centralized due to several reasons. Although waste generation is highly decentralized, decentralized processing has not been attempted on a large scale. A major portion of the solid waste is biodegradable organic matter which is not suitable for incineration, pyrolysis, etc. This organic waste has high moisture content. However, composting technology seems to be a

*For correspondence. (e-mail: ghoshsukh@gmail.com) good alternative for managing municipal organic solid waste $^{2}$.

Tremendous importance is being given to the composting of solid waste because of its eco-compatibility and its effortless operational procedures. Successful conversion of organic matter into simple organic nitrogen and carbon units is the fundamental functional process of composting. The composting of organic solid waste and the ability of using this composted manure as soil provide a more promising alternative to landfills or incineration, which are known to cause extreme levels of pollution. Composting can handle fairly large quantities of organic wastes in a very sustainable manner. It is one of the prime components of integrated waste management strategy, utilized for the recycling of organic waste into useful products. The composted municipal waste not only imparts a fairly stable form of organic matter, but also is a source of plant nutrients that increase the fertility and productivity of soils ${ }^{1}$.

In organic solid waste degradation, the overall effectiveness of organic waste breakdown is dependent on microbes and their metabolic activities. Microorganisms make use of various kinds of substrates available in the organic waste using a large array of hydrolytic enzymes. These enzymes are known to escalate the degradation process. The enzymes released by the microorganisms during composting disintegrate a number of complex organic compounds into small water-soluble molecules ${ }^{3}$. Microbial diversity is a crucial requirement for successful composting process. A variety of mesophilic, thermotolerant and thermophilic, aerobic microorganisms (e.g. bacteria, fungi, yeasts and actinomycetes) are known to be involved in the composting process. Their inclusion into the soil is proven to improve soil structure and have other beneficial effects ${ }^{4}$.

Nisargruna biogas technology, developed at Bhabha Atomic Research Centre, Mumbai, India has become a popular and useful technology in processing organic solid waste in the country ${ }^{5}$. More than 150 such biogas plants of different capacities are working within the country for processing organic solid waste. It is a biphasic biodegradation process where aerobic hydrolysis (predigester) is 
followed by anaerobic methanogenesis. The aerobic hydrolytic predigestion chamber (predigester) is rich in microorganisms which can degrade complex biomolecules very fast. There is variation in the composition of aerobic predigester microflora depending on the geographic location, climatic conditions and feed material used ${ }^{6}$.

In this study, aerobic predigester microflora from three Nisargruna plants were used singly or in different combinations to obtain fast-composting microflora. Two of these plants are located in Mumbai and process household organic kitchen waste, whereas the third plant is located at Matheran, Maharashtra and processes a combination of kitchen waste and horse dung. A combination of two specific predigester microflora was found to give fast aerobic degradation of organic kitchen waste within a period of four days. In the present study, the fast composting microflora, developed by the above method, were characterized by $16 \mathrm{~S}$ rRNA metagenomics of the V3-V4 region along with physico-chemical properties of the resultant compost. The study shows the development of a system that can degrade common household organic waste in a short time (four days) and it also reports the microbial diversity in a temporal manner by partial rRNA metagenomics analysis. This has huge potential in decomposing urban organic waste in a distributed manner, and reduces the load of organic solid waste management of urban local bodies (ULBs).

\section{Materials and methods}

\section{Production and maintenance/development of compost system}

First, $2000 \mathrm{~g}$ of double autoclaved Nisargruna manure (used here as holding material) was added to a plastic container of $34 \mathrm{~cm} \times 22 \mathrm{~cm} \times 26 \mathrm{~cm}(l \times w \times h)$ with $0.5 \mathrm{~cm}$ wide and $15 \mathrm{~cm}$ long slits all around. It was sprinkled with $200 \mathrm{ml}$ Nisargruna biogas predigester slurry ${ }^{5}$. To this, $250 \mathrm{~g}$ of chopped vegetable and fruit waste was added. The degradation of waste material was monitored visually for the next $96 \mathrm{~h}$. Blackening and change in tissue consistency were the primary indicators of biodegradation. When a combination of two different predigester microflora was used, $100 \mathrm{ml}$ slurry from each predigester was mixed and used. The compost containers in which fast degradation of organic waste was observed, were maintained by adding $250 \mathrm{~g}$ of chopped vegetables every fourth day. Three baskets of the selected fast compost system were monitored on a daily basis and different physico-chemical properties were studied as described below.

\section{Physico-chemical characterization of compost system}

The chemical and physical characteristics of the developed compost system were studied by standard methods.
The $\mathrm{pH}$, total organic carbon (TOC), total nitrogen (TN) content, moisture content (MC), water holding capacity (WHC), electrical conductivity (EC), bulk density and phytotoxicity of the fresh compost samples were determined at regular intervals. Five sub-samples were taken randomly from different positions and depths of the basket, and were mixed and kept in a sterile plastic ziplock pouch. Samples were taken from this pouch for physicochemical analysis. For monitoring temperature, three thermometers were inserted randomly but away from each other in the basket at a depth of 3 " and average temperature of the compost basket was recorded. Using a calibrated digital ELICO $\mathrm{pH}$ meter, $\mathrm{pH}$ and EC of the compost water extract $(1: 5)$ were measured. The temperature and $\mathrm{pH}$ of compost sample were recorded daily ${ }^{1,7}$. Bulk density of the compost samples was calculated by dividing the weight of compost material by volume of the material in the container ${ }^{7}$.

Quantitative estimation of TOC and TN was carried out (ThermoFinnigan CHNS analyzer). For this, $3 \mathrm{mg}$ of dried and ground compost samples were used.

$\mathrm{MC}$ was measured by drying pre-weighed fresh compost samples at $105^{\circ} \mathrm{C}$ for approximately $24 \mathrm{~h}$ in a hot-air oven. MC (\%) was calculated as ${ }^{7}$

$$
\mathrm{MC}=\frac{W_{\mathrm{w}}-W_{\mathrm{d}}}{W_{\mathrm{w}}} \times 100,
$$

where $W_{\mathrm{w}}$ is the wet weight of sample and $W_{\mathrm{d}}$ the dry weight of sample.

Fresh compost samples of known initial moisture content were weighed to determine WHC. The amount of water retained by the dry sample ( $g$ water/g dry material) was calculated as ${ }^{7}$

$$
\mathrm{WHC}=\frac{\left(W_{\mathrm{s}}-W_{i}\right)+\mathrm{MC} \times W_{i}}{(1-\mathrm{MC}) \times W_{i}},
$$

where $W_{i}$ is the initial weight of sample, $W_{s}$ the final weight of sample and MC is the initial moisture content.

The phytotoxicity bioassay was performed to test the compost maturity. Vigna radiata seeds were used for this bioassay because of their rapid and easy germination. For evaluation of phytotoxicity of the developed compost, $50 \mathrm{~g}$ of compost samples was mixed with $100 \mathrm{ml}$ distilled water ${ }^{8}$. The aqueous mixture was prepared by shaking for $1 \mathrm{~h}$ at $25^{\circ} \mathrm{C}$ and then filtered. The resultant filtrate was diluted with distilled water to yield $0 \%, 25 \%, 50 \%, 75 \%$ and $100 \%$ compost extract. Therefore $0 \%$ indicates distilled water, while $25 \%$ indicates $1: 4$ dilution of the compost extract and $100 \%$ indicates neat extract. Seeds of $V$. radiata were placed on compost extracts moistened filter paper. A distilled water control was maintained with three replicates. After incubation at $25^{\circ} \mathrm{C}$ for $72 \mathrm{~h}$ in the dark, germinated seeds were counted $(G)$ and root 
length, $(L \mathrm{~cm})$ were measured. The percentage of seed germination and germination index (GI) were calculated as $^{8,9}$

Seed germination $(\%)$

$$
=\frac{\text { No. of seeds germinated in compost extract }}{\text { No. of seeds germinated in control }} \times 100 \text {. }
$$

Root elongation (\%)

$$
=\frac{\text { Mean root length in compost extract }}{\text { Mean root length in control }} \times 100 \text {, }
$$

$$
\mathrm{GI}=\frac{G}{G_{0}} \times \frac{L}{L_{0}} \times 100,
$$

where $G_{0}$ and $L_{0}$ are the germination percentage and root length $(\mathrm{cm})$ respectively, of the distilled water grown plants, and $G$ and $L$ are the corresponding parameters of test samples.

\section{Maturity analysis by Solvita® test}

The Solvita test was performed following the manufacturer's protocol (Solvita ${ }^{\circledR}$ Updated version 9.0., Woods End Laboratories, USA, 2013). Compost samples were adjusted with optimum moisture content (60-80\% of the sample's WHC) and filled in the provided jar up to the fill line. The jars were tapped to ensure removal of air pockets. The probes with the reactive gel were pegged in the sample jar. The jars were kept at room temperature $\left(20^{\circ}-25^{\circ} \mathrm{C}\right)$ and away from sunlight for $4 \mathrm{~h}$. The colour of the gel probes was noted and compared with the manufacturer's standard colour chart. A Solvita ${ }^{\circledR}$ maturity index was then obtained using compost maturity calculator. The Solvita kit technology is based on the measurement of continuously evolving $\mathrm{CO}_{2}$ and the volatile ammonia from the compost material.

\section{S rRNA metagenomic sequencing of compost consortia}

Bacterial 16S rRNA hyper variable V3-V4 region was amplified using specific primer pairs for metagenomic study utilizing the Illumina sequencing platform. Total DNA was isolated from each sample $(24 \mathrm{~h}$ and $72 \mathrm{~h}$ ) and $25 \mathrm{ng}$ of DNA was used for PCR amplification with KAPA HiFi Hot start Ready Mix. The PCR involved an initial denaturation of $95^{\circ} \mathrm{C}$ for $5 \mathrm{~min}$ followed by $25 \mathrm{cy}-$ cles of $95^{\circ} \mathrm{C}$ for $30 \mathrm{sec}, 55^{\circ} \mathrm{C}$ for $45 \mathrm{sec}$ and $72^{\circ} \mathrm{C}$ for $30 \mathrm{sec}$ and a final extension at $72^{\circ} \mathrm{C}$ for $7 \mathrm{~min}$. The amplicons were purified using Ampure beads to remove unused primers. The final amplicon concentration of $24 \mathrm{~h}$ sample and $72 \mathrm{~h}$ sample was 58.9 and $62.8 \mathrm{ng} / \mu \mathrm{l}$ respectively, after purification. Sequencing was performed using Illumina Miseq with 2x300PE V3 sequencing kit. The sequence data quality was checked using FastQC and MultiQC software. The data were checked for base call quality distribution, \% bases above Q20, \%GC, and sequencing adapter contamination. The QC passed reads were imported into mothur and the pairs were aligned with each other to form contigs ${ }^{10}$. The contigs were screened for errors and only those between 300 and $540 \mathrm{bp}$ were retained. The gaps and the overhang at the ends from the contigs were removed and processed for chimera removal, which may have formed due to PCR errors using UCHIME algorithm. The filtered contigs were processed and classified into taxonomical outlines based on the GREENGENES v.13.8-99 database. The contigs were then clustered into operational taxonomic units (OTUs). After the classification, OTU abundance was estimated. PICRUSt was used to predict gene family abundance ${ }^{11}$. The $16 \mathrm{~S}$ rRNA copy numbers were normalized by PICRUSt's precalculated files. The metagenomes were predicted using predict_metagenomes.py script ${ }^{11}$. Other statistical analyses and graphs were made using $\mathrm{R}$ and Microsoft Excel. The percentage increase/ decrease of each phyla or order was determined by calculating increase/decrease in the number of OTUs or reads normalized from mothur excel file.

\section{Morphological and cultural characterization of compost microflora}

Various groups of organisms were isolated from the developed composting system $(72 \mathrm{~h})$. Serial dilution of $1 \mathrm{~g}$ compost sample was carried out and $100 \mu \mathrm{l}$ of each of the dilutions was further spread-plated onto selective medium. These plates were further incubated for $24-72 \mathrm{~h}$ at various temperature ranges for observation of bacterial and fungal growth. The fungal cultures were screened and isolated on sterile potato dextrose medium.

On obtaining well-separated colonies, individually distinct and dominant colonies were selected and streaked on the respective media slants and were maintained at $4^{\circ} \mathrm{C}$ for further experimental analysis and enrichments. The preliminary morphological studies were carried out by Gram staining of bacterial isolates and lacto phenol cotton blue mounts of fungal isolates.

\section{Genomic DNA extraction of isolated organisms, PCR amplification of 16S/18S rRNA and sequencing}

The genomic DNA of all bacterial isolates as selected above was extracted by phenol:chloroform: isoamlyalcohol method. The genomic DNA of fungal isolates was extracted by phenol:chloroform method. The 


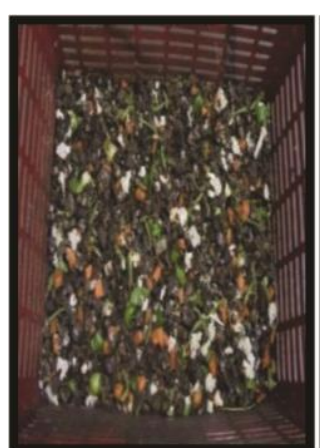

$\mathbf{0 ~ h}$

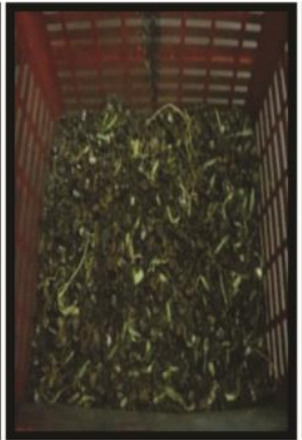

24 h

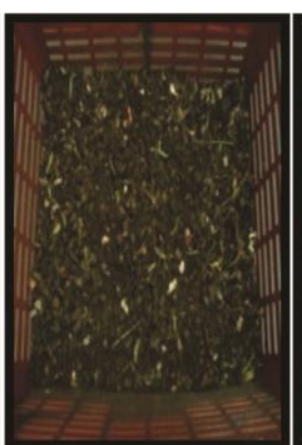

$48 \mathrm{~h}$

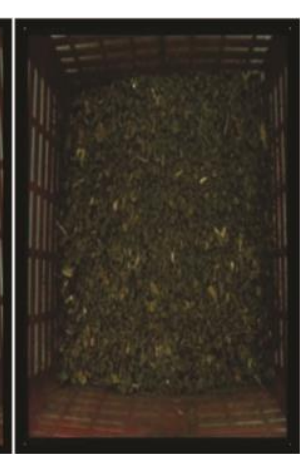

72 h

Figure 1. Degradation of kitchen waste in compost container.

genomic DNA was then stored at $-20^{\circ} \mathrm{C}$ until used for PCR amplification. Primers used for 16S rRNA amplification were U16SF:5'AGAGTTTGATCMTGGCTCAG3'; U16SR:5'TACGGYTACCTTGTTACGACTT3' (ref. 12). The primers used for 18S rRNA amplification were NS1F: 5'GTAGTCATATGCTTGTCTC3'NS2R:5'GGCT GCTGGCACCAGACTTGC3' (ref. 13). The genomic DNA of all bacterial and fungal isolates was amplified by the Touchdown PCR in a CG Palm cycler as described below.

The PCR reaction mixture consisted of $25 \mu$ s solution containing $1 \mu \mathrm{l}$ genomic DNA template (from $1: 100$ dilution of original extract), $1 \mu \mathrm{l}$ of forward and reverse primer $(100 \mathrm{pmol} / \mu \mathrm{l})$, and $12.5 \mu \mathrm{l}$ of $2 \mathrm{X}$ PCR Taqmixture (HiMedia, India) and $9.5 \mu \mathrm{l}$ of sterile water.

For $16 \mathrm{~S}$ rRNA amplification, preheating at $95^{\circ} \mathrm{C}$ for $4 \mathrm{~min}$, denaturation at $95^{\circ} \mathrm{C}$ for $30 \mathrm{sec}$, annealing at $54^{\circ}-$ $46^{\circ} \mathrm{C}$ for $1 \mathrm{~min}$ (30 cycles), extension at $72^{\circ} \mathrm{C}$ for $1 \mathrm{~min}$ followed by final extension at $72^{\circ} \mathrm{C}$ for $5 \mathrm{~min}$ were carried out.

For $18 \mathrm{~S}$ rRNA amplification, preheating at $95^{\circ} \mathrm{C}$ for $4 \mathrm{~min}$, denaturation at $95^{\circ} \mathrm{C}$ for $30 \mathrm{sec}$, annealing at $50^{\circ}-$ $40^{\circ} \mathrm{C}$ for $1 \mathrm{~min}$, extension at $72^{\circ} \mathrm{C}$ for $1 \mathrm{~min}$ (30 cycles) followed by final extension at $72^{\circ} \mathrm{C}$ for 5 min was carried out.

The PCR products were visualized by electrophoretic separation on $1.5 \%$ agarose gel. Synthesis of primers and PCR amplicon sequencing were carried out at Eurofins Genomics India Pvt Ltd, Bengaluru, Karnataka.

\section{Phylogenetic analysis of 16S/18S rRNA sequences of isolated compost microflora}

DNA sequences of the identified bacterial isolates from the compost were used to generate a multiple sequence alignment (MSA) with the Clustal Omega web server, (www.ebi.ac.uk/Tools/msa/clustalo). The generated MSA was used to perform basic phylogenetic analysis with the help of ClustalW2-Phylogeny tool available at the EMBL-EBI (www.ebi.ac.uk/Tools/phylogeny/clustalw2- phylogeny/). MSA of DNA of the organism acts as an input and the parameters are set. The clustering method used here is the neighbour-joining method. The main output is a phylogenetic tree, with both the tree data in the widely used Newick format. This format is used to view diagrammatic representation of the tree using MEGA version 6 , a standalone tree viewing program ${ }^{14}$.

Forty-four rRNA gene sequences from isolated colonies have been deposited with GenBank (accession nos. KY485260 till KY485303) in the sequence read archive (https://www.ncbi.nlm.nih.gov/nuccore/?cmd=historysear ch\&querykey=1).

\section{Results and discussion}

\section{Production and maintenance of compost in the laboratory}

Among different compost containers initiated using aerobic microflora of different Nisargruna predigester plants, one particular compost basket showed fast degradation of vegetable/fruit waste within $96 \mathrm{~h}$ (Figure 1). There was no foul odour or any nuisance caused. The final mature compost was a blackish, humus-rich soil-like product, with an earthen smell. This compost also acted as inoculum for the next batch of vegetable waste added to the basket. Such a basket was maintained by adding $250 \mathrm{~g}$ of shredded kitchen waste periodically (every fourth day) and was multiplied into several baskets.

\section{Physico-chemical studies of compost samples}

The $\mathrm{pH}$ of the compost samples was monitored, starting from $0 \mathrm{~h}$, i.e. the time when the vegetables were added, till $96 \mathrm{~h}$. It was observed that the $\mathrm{pH}$ dropped in 24-48 h after addition of vegetables, with increase in $\mathrm{pH}$ after $48 \mathrm{~h}$. During this study, $\mathrm{pH}$ values were found to be ranging from 8.2 to 8.8 over a period of $96 \mathrm{~h}$ (Figure $2 \mathrm{a}$ ). At the initial stage of composting, $\mathrm{pH}$ value decreased due to production of organic acids from hydrolysis of larger 

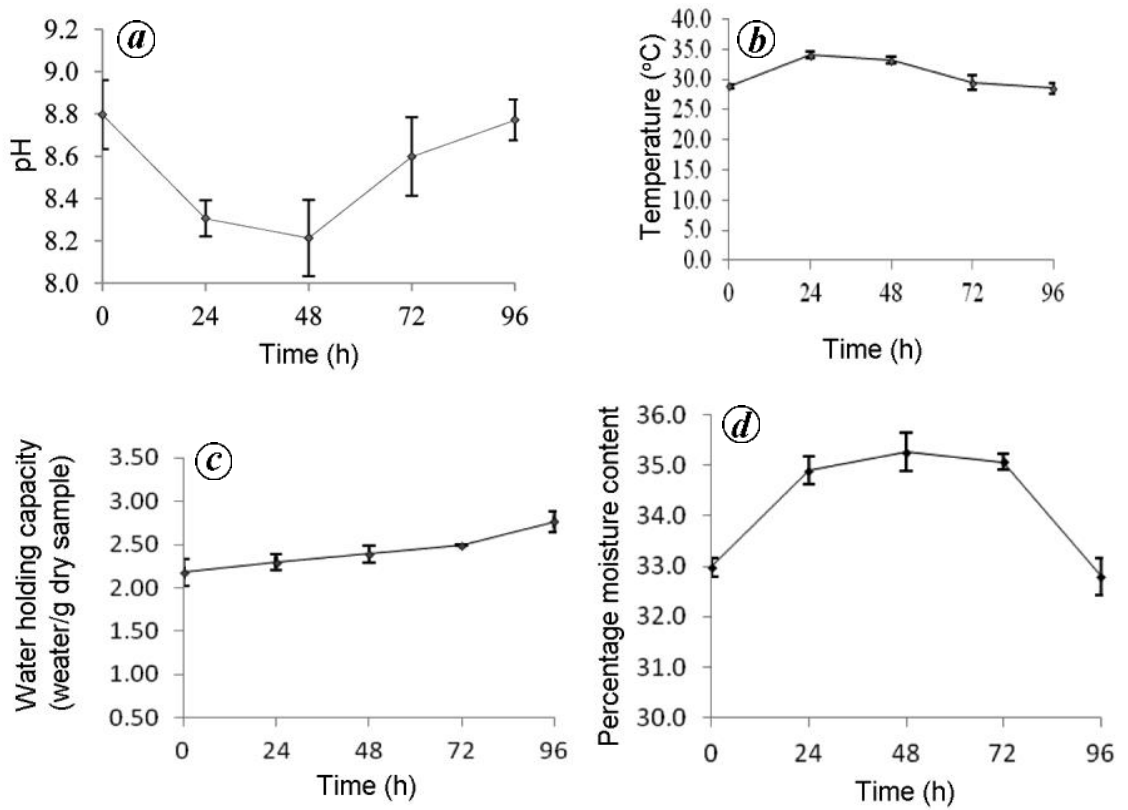

Figure 2. Physico-chemical properties $(\boldsymbol{a}) \mathrm{pH},(\boldsymbol{b})$ temperature, $(\boldsymbol{c})$ water holding capacity and $(\boldsymbol{d})$ moisture content of the composting system.

Table 1. Physico-chemical characteristics of developed compost samples after $96 \mathrm{~h}$

\begin{tabular}{lccc}
\hline Parameters & Units & $\begin{array}{c}\text { Physico-chemical } \\
\text { study results }\end{array}$ & $\begin{array}{c}\text { Recommended } \\
\text { standards }\end{array}$ \\
\hline Electrical conductivity & $\mathrm{dS} / \mathrm{m}$ & 6.16 & $2-6$ (ref. 19) \\
Bulk density & $\mathrm{g} / \mathrm{cm}^{3}$ & 0.61 & 0.61 (ref. 19) \\
Total organic carbon & $\%$ & $15-16$ & $>10$ (ref. 1) \\
Total nitrogen & $\%$ & $1.7-2.0$ & $1.0-3.0$ (ref. 23) \\
$\mathrm{C}: \mathrm{N}$ ratio & - & $7.3-8.1$ & $<25^{*}$ \\
\hline
\end{tabular}

*Limit for organic matter and $\mathrm{C}: \mathrm{N}$ ratio specified by the United States Environmental Protection Agency in accordance with Waste Licensing under the Waste Management Act 1996.

biomolecules like carbohydrates, proteins and lipids. Thereafter, the $\mathrm{pH}$ began to rise and reached 8.8. This increase in $\mathrm{pH}$ may occur because of the organic acids getting further degraded to small molecules like $\mathrm{CO}_{2}$ and $\mathrm{NH}_{4}$ (ref. 15). The $\mathrm{pH}$ values as observed in this study are in accordance with previous observations of White et al. ${ }^{16}$. An alkaline $\mathrm{pH}$ is known to enhance the composting process and also control pathogenic fungi that prefer acidic growth conditions ${ }^{17}$. EC of this composting system was observed to be $6.16 \mathrm{dS} / \mathrm{m}$. An EC value higher than $4 \mathrm{dS} / \mathrm{m}$ is positively correlated with inhibition of germination of plant seeds ${ }^{18,19}$. The bulk density observed in this study was $0.61 \mathrm{~g} / \mathrm{cm}^{3}$ (Table 1 ). This value is in the recommended range as suggested by Reyes-Torres et al. ${ }^{20}$.

Temperature is considered as one of the real-time indicators of any composting process. It directly relates microbial activity with the degradation of organic material $^{21}$. The temperature in this compost system was observed in the $28-34^{\circ} \mathrm{C}$ range (Figure $2 b$ ). We hypo- thesize that the rise in the temperature during $24-48 \mathrm{~h}$ indicates initial active mesophilic and moderately thermophilic degradation phase in this composting system. During 72-96 h, temperature gradually came down to ambient because of reduced microbial activity resulting from lower availability of organic material (Figure $2 b$ ). Therefore, we conclude that the composting system as developed here is a mesophilic composting system. These results are in the recommended range as observed earlier ${ }^{4}$.

TOC content is an important parameter for judging the completion of composting. Many researchers observed TOC in the range of $20 \%$ or less at the completion of composting ${ }^{1}$. The initial organic carbon content of the substrate (vegetable waste) was $38.13 \%$ (Table1) and nitrogen content was $2.4 \%$. However, TOC content of the mature compost samples ranged between $15 \%$ and $16 \%$ (Table 1) in this study. Thus, the loss of organic carbon during composting stages showed the utilization of vegetable waste by the microbial consortium. It can be 
assumed that a part of carbon residues evolved as $\mathrm{CO}_{2}$ and a part was assimilated by the microbial biomass ${ }^{22}$. Likewise, the TN content reduced to the level of $1.9 \%$ $2.0 \%$ in the mature compost in this study (Table 1). The measure of TN content includes both organic and inorganic forms of nitrogen in developed compost samples. These values are in the recommended range of a good compost ${ }^{23}$.

The $\mathrm{C} / \mathrm{N}$ ratio of the mature compost samples ranged from 7.3 to 8.1 (Table 1), which is within the limits specified by the United States Environmental Protection Agency Waste Management Act, 1996. A C/N ratio less than 20 is indicative of an acceptable compost maturity and manure with such ratio is ideal for nursery plant production, although a ratio of 15 or even less is preferable ${ }^{24}$. Similar studies indicated that composted materials having $\mathrm{C} / \mathrm{N}$ ratio less than 20 do not cause $\mathrm{N}$ starvation when applied to soil. The $\mathrm{C} / \mathrm{N}$ ratio is one of the most important parameters that determine the extent of composting and degree of compost maturity. The observed $\mathrm{C} / \mathrm{N}$ ratio in this study clearly indicates that within $96 \mathrm{~h}$, the regular kitchen waste is getting decomposed into mature compost.

WHC is the amount of water held in the pores after gravitational loss for a specified time. WHC of the compost was in the range $2-3 \mathrm{~g}$ water/g dry compost (Figure $2 c$ ). In this study WHC of the compost increased over the period of composting. This indicates that the amount of water held in the pores increases with the progress of composting. These results are in agreement with the standard composting process as observed by Shyamala and Belagali ${ }^{1}$. The MC of the compost was in the range $32-35 \%$ (Figure $2 d$ ). The reduction in MC during composting process is caused by the heat generated by the microbial growth and metabolism. The highest MC was seen in the active mesophilic phase, with approximately $2.5 \%$ decrease occurring till $96 \mathrm{~h}$. Moisture loss during the composting process can be considered as an indicator of the decomposition rate because the heat generation that accompanies decomposition causes evaporation ${ }^{25}$. Moisture appeared to be a key influencing factor for microbial activity as low MC inhibits the growth of beneficial microorganisms while excess moisture can create anaerobic conditions, leading to the production of unpleasant odours and toxic volatile substances ${ }^{17}$.

Phytotoxicity response in plants has been exploited as an index of compost maturity. In this study, phytotoxicity of compost extracts was evaluated by seed germination technique of $V$. radiata. The number of seeds germinated was counted after 24, 48 and $72 \mathrm{~h}$. After $72 \mathrm{~h}$, root length of all the seeds was individually measured. Further, germination percentage and germination index (\%) were calculated.

We observed that $25 \%$ of compost extract (i.e. $1: 4$ dilution) exhibited $100 \%$ germination of seeds (Figure $3 a$ ). The root length of germinated seeds decreased with the increasing filtrate concentration (Figure $3 b$ ). An average final germination index was $84 \%$ (Figure $3 c$ ). It revealed that a maximum of $25 \%$ of compost can be used for field applications without any deleterious effects. Moreover, root length also increased over a period of composting. The decrease in toxicity over the period of composting is probably due to reduction in the organic acids as a result of microbial activity in the compost. A germination index higher than $80 \%$ indicates absence of phytotoxicity $^{8,9}$. It may also be noted that the ability of the compost to inhibit germination of weed seeds is considered desirable and characteristic of mature compost. The present findings are in accordance with the observations of Mitelut and $\mathrm{Popa}^{8}$, and Zucconi et al. ${ }^{9}$.

The Solvita compost maturity test is another accepted method included in the VSWMR (Virginia Solid Waste Management Regulations, Virginia Register of Regulations, 2011), and is widely recognized and validated. The Solvita ${ }^{\circledR}$ test indicated that the composting system was in the highly active phase of degradation and no free ammonia was released during $24 \mathrm{~h}$ and $48 \mathrm{~h}$, according to the Solvita ${ }^{\circledR}$ CMI calculator. The concentration of $\mathrm{CO}_{2}$ was found to be $45,459 \mathrm{ppm}$ and $\mathrm{NH}_{3}$ was $<10 \mathrm{ppm}$ at $24 \mathrm{~h}$, whereas $\mathrm{CO}_{2}$ level reduced to $9215 \mathrm{ppm}$ in $48 \mathrm{~h}$ and the quantity of evolved $\mathrm{NH}_{3}$ remained unchanged. At $96 \mathrm{~h}$, $\mathrm{CO}_{2}$ concentration was found to be $1868 \mathrm{ppm}$ and $\mathrm{NH}_{3}$ levels were $<10$. The compost was cured and had low respiration indicating its readiness to be used as a soil conditioner. Further, the seventh day compost sample showed no further change in parameters compared to that of $96 \mathrm{~h}$ on Solvita ${ }^{\circledR}$ test (Supplementary Figure 1). This also indicates that $96 \mathrm{~h}$ sample is ready for soil application. Therefore, Solvita ${ }^{\circledR}$ test confirmed completion of the composting process.

\section{Comparative metagenomic analysis of mesophilic and mature phase of the developed composting system}

The 16S rRNA V3-V4 region-based metagenomic analysis of $24 \mathrm{~h}$ (mesophilic phase) and $72 \mathrm{~h}$ (mature phase) compost samples was carried out. We hypothesize that the $24 \mathrm{~h}$ time point represent the active phase, whereby degradation of organic matter by the metabolically active mesophilic bacteria was carried out, and that the $72 \mathrm{~h}$ time point represents the mature phase of this developed sustainable composting system.

A total of 169,492 reads were obtained from the sequencing of the active mesophilic phase $(24 \mathrm{~h})$ sample. However, after processing and statistical analysis, a total of 47,564 high-quality reads were recorded from which 296 different OTUs were identified. The seven most abundant phyla in this composting phase were Proteobacteria, Firmicutes, Bacteroidetes, Actinobacteria, Planctomycetes, Chloroflexi and Verrucomicrobia (Supplementary 

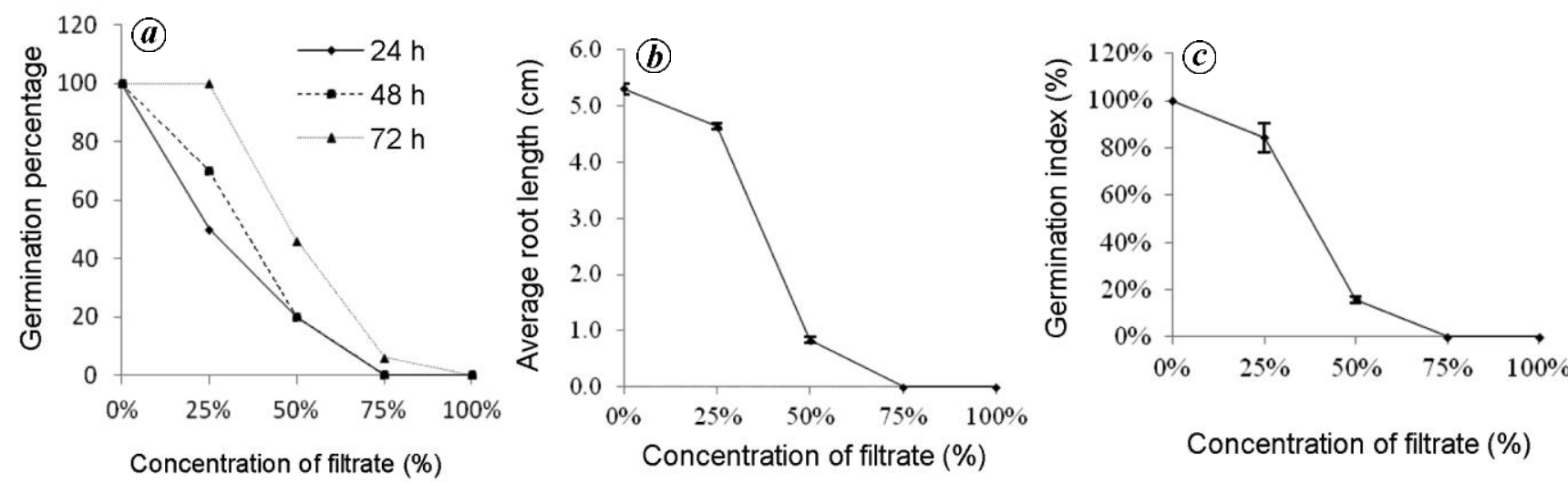

Figure 3. (a) Germination percentage, (b) average root length and (c) germination index at effective filtrate concentrations.

Figure 2). Most of the phyla have been well reported in the literature for their abundance in the mesophilic composting, albeit without any reference to the proportion of each of them in the context of total bacterial population ${ }^{26}$. These seven phyla accounted for $94 \%$ of all the reads. In the mature composting phase, a total of 428,894 reads were obtained from the sequencing but after processing and statistical analysis, a total of 95,425 high-quality reads were recorded from which 446 different OTUs were identified. The seven most abundant phyla in the mature phase were Proteobacteria, Bacteroidetes, Firmicutis, Planctomycetes, Actinobacteria, Verrucomicrobia and Chloroflexi (Supplementary Figure 2). These seven phyla accounted for $95.1 \%$ of the total OTUs. Although mature phase sample showed presence of the same seven phyla as reported in the active phase sample, the relative abundance varied widely (Table 2). For example, Proteobacteria population had reduced to $33 \%$ in the mature phase compost compared to $56 \%$ in the active phase compost, while the populations of Bacteroidetes (from 15\% to $21 \%$ ) and Planctomycetes (from $10 \%$ to $24 \%$ ) increased significantly in the mature phase compost. There was a substantial presence of microbes belonging to the phyla Verucomicrobia in mature compost, while the same phyla contributed a very small population in the active phase (Figure $4 a$ ). The mature sample $(72 \mathrm{~h})$ showed wider diversity at the order level and reported significant presence of Pirellulales, Planctomycetales, Pelagiococcales, Saprospirales and Bacteriodales, while active phase (24 h) showed narrower diversity and reported only three major orders namely Aletromonadales, Marinicellales and Bacillales. Seven major phyla showed significant shifts in abundance throughout the compost process, particularly Planctomycetes and Proteobacteria, while Actinobacteria and Firmicutes did not show significant change in abundance between the two composting phases (Figure $4 a$ ). Organisms of these phyla possess diverse metabolic activity and are often found in soil. The taxonomic diversity as shown by metagenomic analysis of $24 \mathrm{~h}$ and $72 \mathrm{~h}$ compost samples had significant shifts. The dominant organisms of 24 and $72 \mathrm{~h}$ are typically members of Gammaproteobacteria, Alphaprotoebacteria and Delatproteobacteria, which belong to the ubiquinone-containing phylum Protoebacteria (Supplementary Figure 3).

The class Gammaproteobacteria found in the active and mature compost belonged to phylum Proteobacteria. While $81 \%$ of the Proteobacteria in the active phase belonged to Gammaproteobacteria, this class constitutes $60 \%$ of the Proteobacteria population in mature compost. Although the proportions of constituent orders within the class Gammaproteobacteria in two samples remained similar, the order Chromatiales was three times more abundant in the active phase compared to mature compost (Figure $4 b$, I and II). This is a significant observation considering the fact that Chromatiales are microaerophilic, purple sulphur bacteria which play a major role in the carbon and phosphorus cycle. These organisms are also known as primary producers. In any compost system, pockets of microaerophilic conditions develop and presence of these organisms enhances degradation of organic matter under such circumstances ${ }^{27}$. We hypothesize that the presence of high proportion of Chromatiales in the active phase compared to the mature phase is a major contributing factor for the fast degradation of organic matter in this compost system. Although organisms from class Betaprotoebacteria were reported in earlier composting systems in significant abundance, organisms of that class were detected in negligible quantity (less than $1 \%$, both in active and mature phases) in the metagenomics study in the present compost system ${ }^{28}$.

Among the most abundant genera, we highlight Halomonas, Luteimonas, Xanthomonas and Alteromonas in Gammaproteobacteria in both the composting phases. The most abundant genus in both phases of composting was Halomonas, having abundance of $27 \%$ reads of the $24 \mathrm{~h}$ sample. Though it has not been extensively reported in the context of composting process, many reports suggest the possible role of these bacteria in degrading chemical and industrial effluents, including their role as denitrifying bacteria ${ }^{29}$. As the composting progresses, the 
RESEARCH ARTICLES

Table 2. List of relatively abundant genera identified for the predominant phyla in different composting phases

\begin{tabular}{|c|c|c|c|c|c|c|c|}
\hline $\begin{array}{l}\text { Operational } \\
\text { taxonomic } \\
\text { unit }\end{array}$ & Phylum & Class & Order & Family & Genus $^{\mathrm{a}}$ & $\begin{array}{l}\text { Active } \\
\text { phase }^{\text {b }}\end{array}$ & $\begin{array}{l}\text { Mature } \\
\text { phase }^{\mathrm{c}}\end{array}$ \\
\hline OTU525 & Verrucomicrobia & Opitutae & Pelagicoccales & Pelagicoccaceae & Pelagicoccus & 0.15 & 4.22 \\
\hline OTU507 & Proteobacteria & Gammaproteobacteria & Xanthomonadales & Xanthomonadaceae & Luteimonas & 7.25 & 4.00 \\
\hline OTU506 & Proteobacteria & Gammaproteobacteria & Xanthomonadales & Xanthomonadaceae & Unclassified & 1.12 & 2.55 \\
\hline OTU485 & Proteobacteria & Gammaproteobacteria & Oceanospirillales & Halomonadaceae & Halomonas & 27.02 & 11.82 \\
\hline OTU480 & Proteobacteria & Gammaproteobacteria & Marinicellales & Marinicellaceae & Unclassified & 1.97 & 0.06 \\
\hline OTU450 & Proteobacteria & Gammaproteobacteria & Alteromonadales & Alteromonadaceae & Marinimicrobium & 1.93 & 0.13 \\
\hline OTU451 & Proteobacteria & Gammaproteobacteria & Alteromonadales & Alteromonadaceae & Marinobacter & 1.19 & 0.05 \\
\hline OTU406 & Proteobacteria & Alphaproteobacteria & Rhodospirillales & Rhodospirillaceae & Unclassified & 1.18 & 0.59 \\
\hline OTU396 & Proteobacteria & Alphaproteobacteria & Rhodobacterales & Rhodobacteraceae & Unclassified & 5.42 & 5.18 \\
\hline OTU387 & Proteobacteria & Alphaproteobacteria & Rhizobiales & Phyllobacteriaceae & Chelativorans & 0.65 & 2.79 \\
\hline OTU370 & Planctomycetes & Planctomycetia & Planctomycetales & Planctomycetaceae & Planctomyces & 2.10 & 7.86 \\
\hline OTU362 & Planctomycetes & Planctomycetia & Pirellulales & Pirellulaceae & Unclassified & 3.87 & 9.50 \\
\hline OTU367 & Planctomycetes & Planctomycetia & Pirellulales & Pirellulaceae & Planctomycete & 0.09 & 1.05 \\
\hline OTU355 & Planctomycetes & Phycisphaerae & Phycisphaerales & Unclassified & Unclassified & 2.68 & 1.98 \\
\hline OTU199 & Firmicutes & Bacilli & Bacillales & Bacillaceae & Gracilibacillus & 3.61 & 0.55 \\
\hline OTU175 & Chloroflexi & Thermomicrobia & $J G 30-K F-C M 45$ & Unclassified & Unclassified & 1.05 & 0.61 \\
\hline OTU158 & Bacteroidetes & Saprospirae & Saprospirales & Saprospiraceae & Unclassified & 0.71 & 3.98 \\
\hline OTU152 & Bacteroidetes & Rhodothermi & Rhodothermales & Balneolaceae & KSA1 & 8.03 & 9.52 \\
\hline OTU139 & Bacteroidetes & Flavobacteriia & Flavobacteriales & Flavobacteriaceae & Unclassified & 4.40 & 1.30 \\
\hline OTU128 & Bacteroidetes & Cytophagia & Cytophagales & Cyclobacteriaceae & Unclassified & 0.82 & 1.33 \\
\hline OTU115 & Bacteroidetes & Bacteroidia & Bacteroidales & Prevotellaceae & Prevotella & 0.00 & 0.97 \\
\hline OTU069 & Actinobacteria & Actinobacteria & Actinomycetales & Unclassified & Unclassified & 1.78 & 1.80 \\
\hline OTU047 & Actinobacteria & Actinobacteria & Actinomycetales & Micromonosporaceae & Unclassified & 1.58 & 0.06 \\
\hline OTU027 & Actinobacteria & Actinobacteria & Actinomycetales & Dermabacteraceae & Brachybacterium & 0.04 & 1.38 \\
\hline
\end{tabular}

${ }^{\mathrm{a}}$ List of genera with more than $1 \%$ abundance in one of the phases. ${ }^{\mathrm{b}, \mathrm{c}}$ Percentage abundance of genera in active and mature phase.

Halomonas population reduces and at $72 \mathrm{~h}$ it shows $12 \%$ abundance. Luteimonas has been reported to be useful in food waste composting at moderately thermophilic environment ${ }^{30}$, and this genus was present in $7 \%$ and $4 \%$ of total abundance in the mesophilic phase and mature phase respectively, of this compost system. The class Alphaprotoebacteria in mesophilic phase $(17 \%)$ and mature phase (36\%), typically comprised of genera Rhodobacterales (63\%), Rhodospiralles (13\%) and Rhizobiales (17\%) in mesophilic degradation phase; however, the abundance shifted to $44 \%, 5 \%$ and $39 \%$ respectively, in the mature phase of composting. Rhizobiales is an integral part of the nitrogen cycle in soil as well as in any compost system. It plays an important role in denitrification and members of these genus are also known to be important symbiotic nitrogen fixers in the roots of several plants ${ }^{31}$. The class Deltaproteobacteria (2\%) in the mesophilic phase and mature phase remained stable throughout the composting phase with order Myxococcales (72\%) being abundant in the mesophilic phase and GMD14H09_unclassified bacteria $(68 \%)$ in the mature compost phase.

All these genera comprise bacterial species that can thrive and flourish in the mesophilic stage of composting and are hypothesized to play an important role in biomass degradation during the composting process. Abundance of Proteobacteria indicates that they may have a dominant role in the present composting process. Abundance of Proteobacteria in the composting system and its role in humic acid reduction have been well studied ${ }^{32}$. As the composting process is mostly mesophilic in nature, it provides a good niche for the phylum Proteobacteria.

Another predominant phylum of bacteria identified was Firmicutes with less than $10 \%$ presence at the initial and final stages of composting. Major class found in the phylum Firmicutes is Bacilli (98\%) of which genus Gracilibacillus (86\%), Clostridia (1\%) and Bacillus (1\%) dominated in the mesophilic phase. Order Lactobacillales $(5 \%)$ is another important constituent in this phylum. The population of phylum Bacilli $(57 \%)$ and Clostridia $(35 \%)$ showed wide shifts in the final phase of composting. The diversity at the genus level showed significant variation, validating the two critical phases of composting. Members of phylum Firmicutes are known to generate heat during active stages of growth in composting and are resistant to temperature fluctuations ${ }^{32}$. Thus, the present data indicate that as the Proteobacteria population reduces, Firmicutes population increases beyond the mesophilic stages of composting. Firmicutes has been reported in the literature to be found in manure and organic compost. It is hypothesized to play an important role in biomass degradation during the composting process ${ }^{33}$.

Phylum Bacteroidetes accounted for $15 \%$ of total bacteria at the active phase of degradation (Figure $4 a$ ). The order Rhodothermales (54\%) was the most abundant, followed by Flavobacteriales (32\%), Cytophagales (8\%) and Saprospirales $(5 \%)$. As the compost matured, 

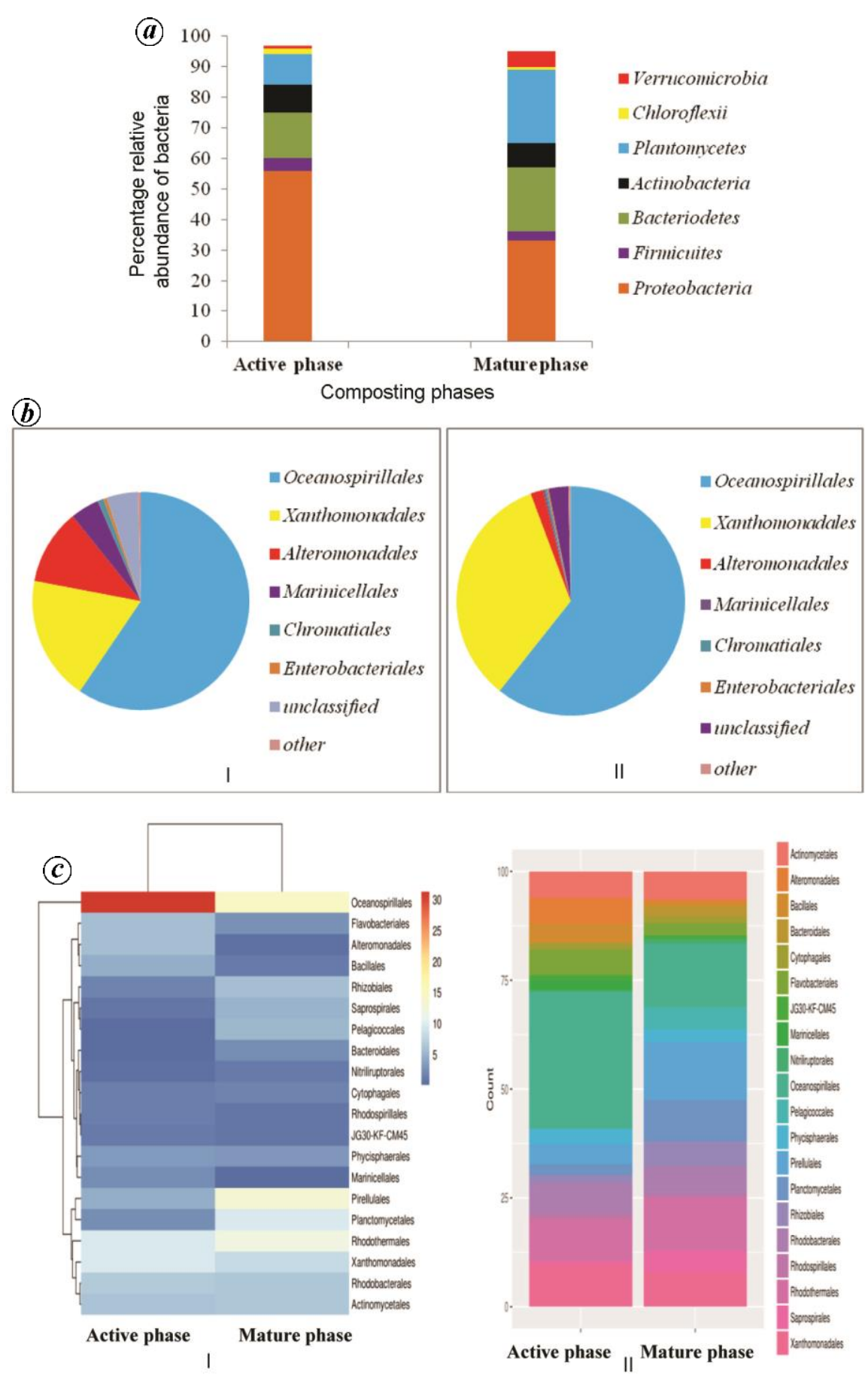

Figure 4. $\boldsymbol{a}$, Relative abundance of dominant phyla. $\boldsymbol{b}$, Distribution of class Gammaproteobacteria in the active (I) and mature phase (II). $\boldsymbol{c}$, Top 20 orders (normalized operational taxonomic units) bar plot (I) and top 20 orders (normalized OTUs) heat map (II).

Bacteroidetes population increased to $21 \%$ and Saprospirales was the most abundant, contributing $19 \%$ of total Bacteroidetes. Members of phylum Bacteroidetes are considered effective degraders of macromolecules. The phylum Actinobacteria consisted of approximately 8-9\% of total bacterial population in both the phases. During degradation phase, the classes identified with relative abundance were Actinobacteria (57\%), Nitrilliruptoria
(11\%), Acidomicrobiia (6\%) and Thermoleophilia (3\%). However, in the mature phase, the classes identified were Actinobacteria (67\%), Nitrilliruptoria (14\%), Coriobacteriia $(2 \%)$ and Acidomicrobiia (2\%). Actinobacteria abundance was similar in all the phases of the compost and in accordance with earlier observations of Takaku et al. ${ }^{32}$. The second most abundant class in this phylum (Actinobacteria) was Nitrilliruptoria, both in active and mature 
phases of the present compost system. This is a unique observation because it has not been previously identified in compost. In this compost system two highly abundant genera in class Nitrilliruptoria are Nitriliruptor and Euzebya. They are known to be microaerophilic, thermophilic and alkaliphilic Actinobacteria. Presence of these organisms makes the compost system highly efficient. Such organisms are known to be fast and efficient degraders of recalcitrant biopolymers, and can operate at very low oxygen concentration ${ }^{34}$. They were studied for utilization of short-chain organic acids, amides and aliphatic nitriles as energy and carbon source by Shivlata et al. ${ }^{34}$. These findings suggest that this compost system can be explored for potential Actinobacteria members with wide biotechnological and environmental applications. The order Actinomycetelaes accounted for $98 \%$ of phylum Actinobacteria in the mature phase. The major genera included Nocardia, Cellulomonas, Arthrobacter, Dietzia, Pseudonocardia and Corynebacterium. The appearances of Corynebacterium were detected in a laboratory-scale food waste composting process by Ishii et $a l .{ }^{35}$.

Phylum Planctomycetes displayed significant shifts in abundance from the mesophilic stage (10\%) to the mature compost stage (24\%; Figure $4 c$, I and II). Planctomycetes is considered a slow-growing decomposer of organic mat$\operatorname{ter}^{36}$. The most abundant genera identified were Planctomyces (20\%), Pirellula (57\%) and Phycisphaerae (33\%) in the mesophilic stage. The abundance of these genera was $33 \%, 46 \%$ and $12 \%$ respectively, in the mature stage of composting. Planctomyces and Pirellula were the commonly detected genera in soils ${ }^{37}$. Phylum Chloroflexi accounted for $4 \%$ of total compost bacteria in the mesophilic compost stage and $1 \%$ in the mature stage. Also, $80 \%$ of phylum Chloroflexi belonged to class Thermomicrobia in the mesophilic phase, while $70 \%$ belonged to class Thermomicrobia in the mature phase. Three abundant genera detected were Sphaerobacter (5\%), Thermomicrobia $(7 \%)$ and Chloroflexi $(4 \%)$ in the active phase of degradation, whereas Sphaerobacter (8\%) and Chloroflexi $(13 \%)$ contributed slightly altered composition in the mature phase. Another genera, Caldilinea was also present $(0.3 \%$ in active phase and $0.9 \%$ in mature phase) in small proportion. Although phylum Chloroflexi has been known to be important in the composting process and is often a dominant group, these genera (Sphaerobacter and Thermomicrobia) have not been widely studied in compost previously ${ }^{38}$. Sphaerobacter has been associated with heavy-metal bioremediation and municipal sewage biodegradation $^{39}$, Caldilinea on the other hand, is known to be an efficient cellulose and hemicellulose degrader ${ }^{40}$. Many members of the class Thermomicrobia fall in the category of extremophiles and have been isolated from desert soil ${ }^{41}$. Filamentous Chloroflexi is a green, nonsulphur bacterium found abundantly in wastewater treatment processes ${ }^{42}$. We hypothesize that congregation of such unique organisms has significantly contributed to efficient and fast biodegradation in the present compost system.

\section{Alpha diversity of microbial consortia at the initial and final phases of composting}

Alpha diversity is a measurement of richness and relative abundance of bacteria within the sample. Figure 5 represents different alpha diversity indices of which Chaol and abundance-based coverage estimator (ACE) represent the richness of the samples, while Shannon, Simpson, InvSimpson and Fisher indicate both richness and relative abundance. To compare the number of taxa in samples by including the number of rare organisms that may have been missed due to under sampling, Chao1 and ACE methods were used. For comparing evenness of taxa in the samples Shannon, Simpson and InvSimpson methods were used. To represent the relationship between the number of species and the number of individuals in those species, Fisher's index was used. From the metagenomic data we can observe that alpha diversity of the mature phase (445 OTUs) is higher compared to the mesophilic phase (295 OTUs). The mature phase scored higher in all the analyses mentioned above (Figure 5). From different alpha diversity measurements, a coherent observation can be made that the final mature composting sample has more diversity and richness within than the active mesophilic phase of composting. Similar observation was made by Luciana et al. ${ }^{42}$ in their study, where the initial and final (mature phase) samples showed higher microbial diversity while intermediate phases (active degradation phases) showed lower microbial diversity.

\section{Morphological and cultural characterization of compost microflora}

Forty-four organisms were isolated and screened from the developed composting system. In this study, the compost container yielded 17 mesophilic, seven thermophilic, three psychrophilic and eight fungal isolates. The bacterial isolates were purified and maintained on nutrient agar slants and fungal isolates were maintained on potato dextrose agar slants. Nine lactic acid bacteria were also obtained. They were purified and maintained on Lactobacillus MRS agar. All the above isolates were stored at $4^{\circ} \mathrm{C}$ until further studies. The classical studies revealed a large population of Gram-negative organisms in mesophilic group and Gram-positive organisms in thermophilic and microaerophilic groups. Three organisms were identified as Acinetobacter pittii, Pantoea agglomerans and Arthrobacter endophyticus, and are known as facultative psychrophiles which can survive in ambient temperature. Such psychrophiles are not unusual and can play an important role in composting when ambient temperature 


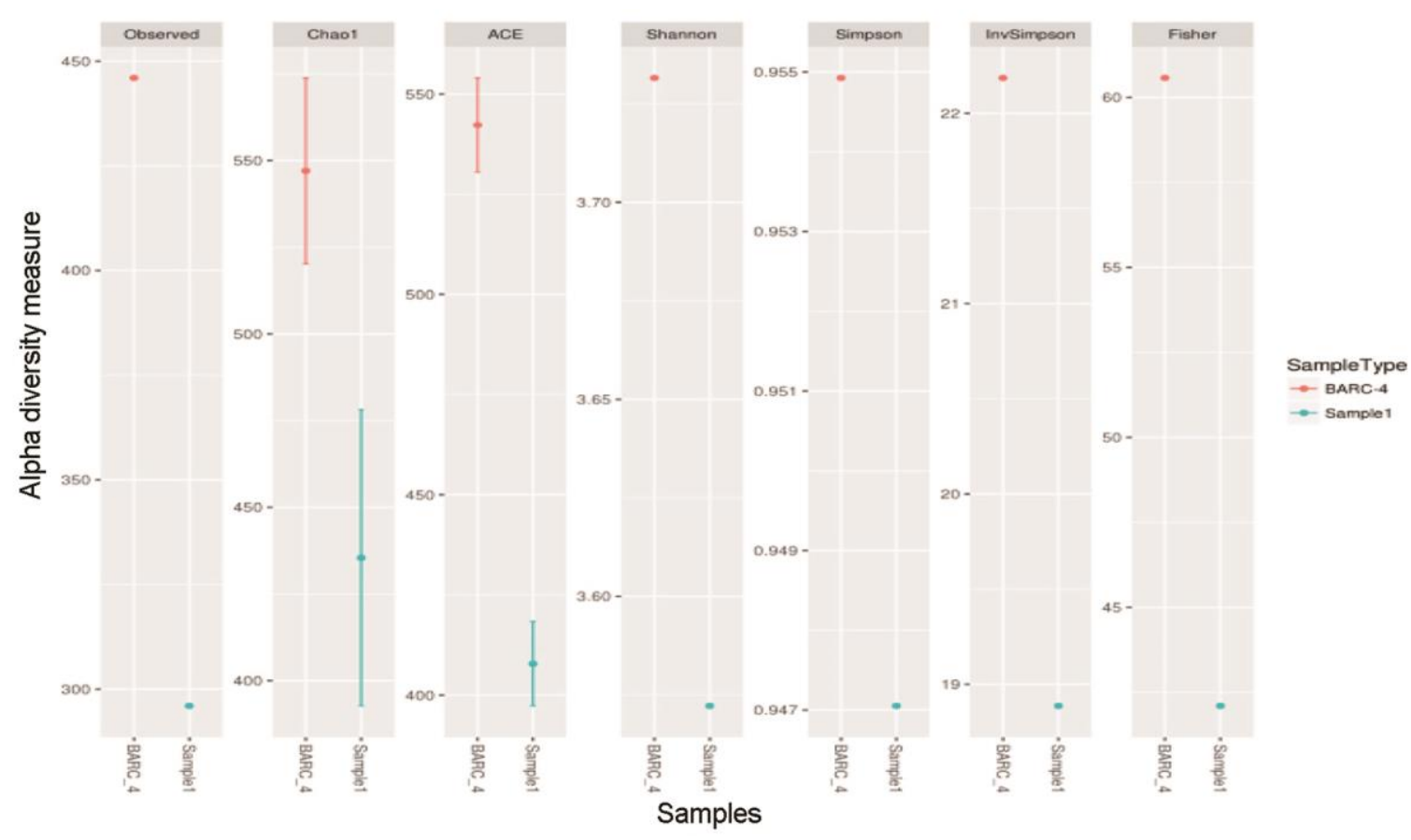

Figure 5. Alpha diversity measurements for initial mesophilic and final mature compost samples; Sample 1: Active phase, BARC 4: Mature phase.

(a)

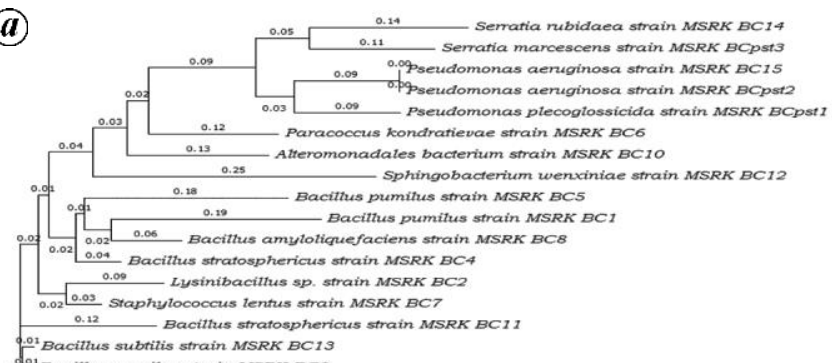

(c)

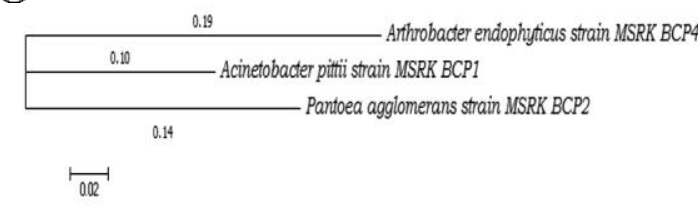

(b)

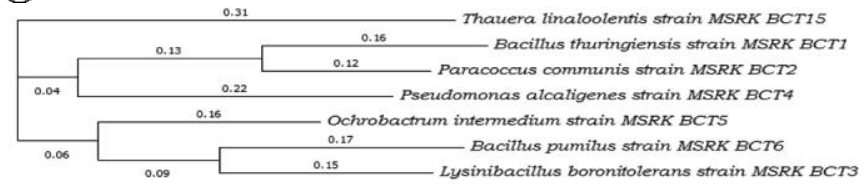

$\stackrel{0.05}{\longrightarrow}$
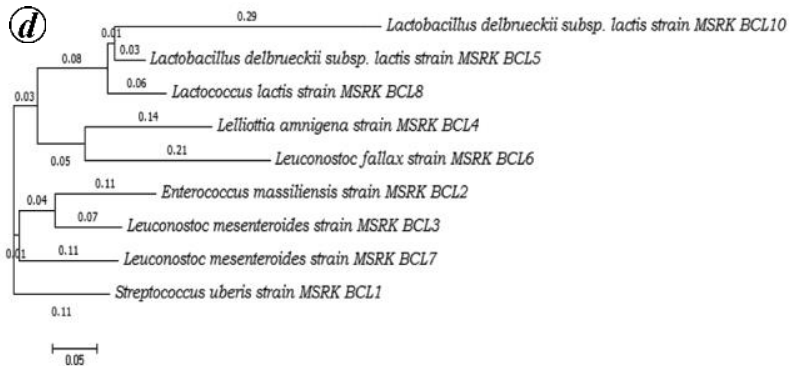

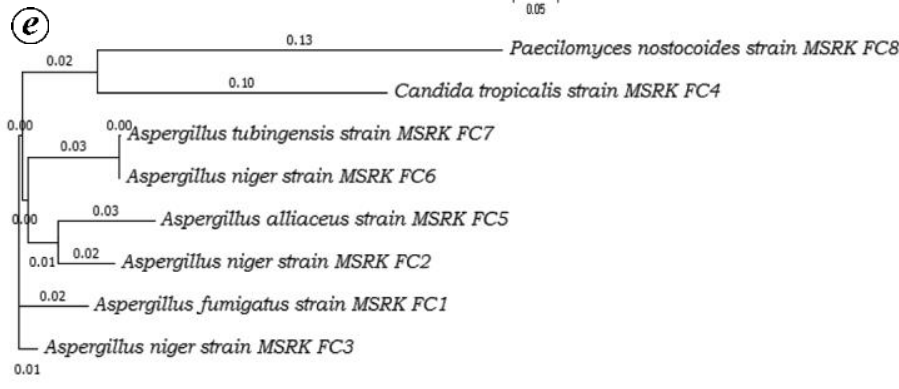

$\stackrel{1005}{0.005}$

Figure 6. Phylogenetic trees of compost microflora based on $16 \mathrm{~S}$ rRNA/18S rRNA by neighbour-joining method. Values are indicated at the nodes $(\boldsymbol{a}-\boldsymbol{e})$. $\boldsymbol{a}$, Based on 16S rRNA sequences of compost mesophilic bacterial isolates. $\boldsymbol{b}$, Based on 16S rRNA sequences of compost thermophilic isolates. $\boldsymbol{c}$, Based on 16S rRNA sequences of compost psychrophilic isolates. $\boldsymbol{d}$, Based on 16S rRNA sequences of compost lactic acid bacteria isolates. $\boldsymbol{e}$, Based on $18 \mathrm{~S}$ rRNA sequences of fungal compost isolates. 
goes down (during late night or predawn or during winter $)^{43}$. The lacto phenol cotton blue mounts showed typical columnar, uni-seriate conidial heads. These fungi were further identified by $18 \mathrm{~S}$ rRNA sequencing. The classical microbiological isolation and identification of organisms in this study was carried out to complement the metagenomics and also to identify fungal species present in this consortium.

\section{PCR amplification, partial 16 S and 18SrDNA gene sequencing and phylogenetic analysis of compost microflora}

The partial 16S rRNA genes of all the bacterial isolates were amplified using 16S Universal primers (Fermentas 16S Universal primers), whereas 18S rRNA partial genes were amplified using 18S Universal primers (Fermentas $18 \mathrm{~S}$ Universal primers) for all the fungal isolates. The $16 \mathrm{~S}$ rRNA amplicon was of $\sim 1000 \mathrm{bp}$ and $18 \mathrm{~S}$ rRNA amplicon was of $\sim 500 \mathrm{bp}$ size. The obtained sequences were aligned and identified using BLAST; the top-10 hits were considered and 98\%-99\% sequence identity was obtained for each of the isolates.

The ClustalW-Phylogeny and Mega6 software was used to construct a phylogenetic tree, which uses neighbor-joining method of tree-building and hence obtained unrooted trees for the groups of organisms. A topological tree showing the phylogenetic relationship between the organisms was obtained for each group of organisms (Figure $6 a-e$ ). The above 44 sequences reported in this study have been deposited under NCBI accession no. KY485260-KY485303 (Supplementary Table 1) in the sequence read archive (https://www.ncbi.nlm.nih.gov/ nuccore $/$ ?cmd=historysearch\&querykey=1). All the bacteria identified by classical microbiology followed by $16 \mathrm{~S}$ rRNA sequencing were also identified by metagenomics and fell under major taxonomic groups reported by metagenomics studies (Supplementary Table 1). This strengthens our observation on the composition of the consortium. The classical microbiological studies were performed to physically isolate the dominant organisms and validate the metagenomics study in terms of the most prevalent taxa present in the consortium. Fungi are known to be effective cellulose degraders. The eight fungi identified in this study were also reported earlier in oil meal waste composting ${ }^{28}$. Fungal genera like Aspergillus, Paecilomyces and Candida, as identified here, are established degraders of lignocellulosic waste. Lignocellulosic wastes are difficult to degrade and presence of these organisms ensures complete degradation of all materials of plant origin, including dry leaves and twigs.

\section{Conclusion}

In this study a sustainable, fast-composting system has been developed. In this system, the compost end-point is achieved at $96 \mathrm{~h}$ post-initiation. This is the fastest reported composting system. There are many efficient hydrolytic bacteria and other physiologically important microorganisms present in this compost consortium. Metagenomic study clearly shows that organisms of order having high hydrolytic ability (e.g. Oceanospirillales, Xanthomonadales, Alteromonadales) representing class Gammaproteobacteria are more abundant in the initial phase of composting ( $24 \mathrm{~h}$ ) compared to the mature phase $(72 \mathrm{~h})$. On the contrary, organisms of orders having ability to assimilate different elements (e.g. nitrogenfixing and sulphur-phosphorus mobilizing Rhizobiales representing class Alphaproteobacteria), increase significantly in the mature phase. Presence of both cellulolytic (Cellulomonas, Caldilinea, etc.) and denitrifying bacteria (Rhizobiales) ensures maximization of the rate of degradation of organic waste in this system. This in turn accelerates the composting process. Presence of Rhizobiales also ensures good quality of this compost. When applied in soil in a standing crop, this compost has the ability to introduce symbiotic nitrogen fixers in significant numbers. The present study also reports potential role of genera Sphaerobacter, Nitriliruptor and Caldilinea in an efficient compost system. It shows enough promise of production of sustainable organic fertilizers using the microbial consortium developed here. This can be used to initiate a pilot plant for composting municipal organic waste. The microbial consortium can further be explored for the degradation of various unique substances, e.g. agricultural crop residues, food processing industry waste, poultry waste, etc. This consortium can be potentially grown as a mixed culture under laboratory conditions, and can be used to compost bulk organic waste in field conditions. Thus, the self-sustaining, fast compost system developed here has potential applications in organic solid waste management.

Conflict of interest: Authors declare no conflict of interest.

1. Shyamala, D. C. and Belagali, S. L., Studies on variations in physico-chemical and biological characteristics at different maturity stages of municipal solid waste compost. Int. J. Environ. Sci., 2012, 2, 1984-1998.

2. Atalia, K. R., Buha, D. M., Bhavsar, K. A. and Shah, N. K., A review on composting of municipal solid waste. IOSR J. Environ. Sci., 2015, 9, 20-29.

3. Benitez, E., Nogales, R., Elvira, C., Masciandaro, G. and Ceccanti, B., Enzyme activities as indicators of the stabilization of sewage sludges composting with Eisenia foetida. Bioresour. Technol., 1999, 67(3), 297-303.

4. Beffa, T. et al., Isolation of thermus strains from hot composts (60 to 80C). Appl. Environ. Microbiol., 1996, 62(5), 1723-1727.

5. Tale, M., Ghosh, S., Kapadnis, B. and Kale, S., Isolation and characterization of microalgae for biodiesel production from Nisargruna biogas plant effluent. Bioresour. Technol., 2014, 169, 328-335.

6. Ghosh, S. B., Bhattacharya, K., Nayak, S., Mukherjee, P., Salaskar, D. and Kale, S. P., Identification of different species of 


\section{RESEARCH ARTICLES}

Bacillus isolated from Nisargruna Biogas Plant by FTIR, UV-Vis and NIR spectroscopy. Spectrochim. Acta Part A, 2015, 148, 420 426.

7. Khater, E. S. G., Some physical and chemical properties of compost. Int. J. Waste Resour., 2015, 5, 1-5.

8. Mitelut, A. A. C. and Popa, M. E., Seed germination bioassay for toxicity evaluation of different composting biodegradable materials. Rom. Biotechnol. Lett., 2011, 16, 121-129.

9. Zucconi, F., Pera, A. and Forte, M., Evaluating toxicity of immature compost. BioCycle, 1981, 2, 54-57.

10. Schloss, P. D. et al., Introducing mothur: open-source, platformindependent, community-supported software for describing and comparing microbial communities. Appl. Environ. Microbiol., 2009, 75, 7537-7541.

11. Langille, M. G. I. et al., Predictive functional profiling of microbial communities using $16 \mathrm{~S}$ rRNA marker gene sequences. Nature Biotechnol., 2013, 31, 814-821.

12. Lane, D. J., 16S/23S rRNA sequencing. In Nucleic Acid Techniques in Bacterial Systematics (eds Stackebrandt, E. and Goodfellow, M.), John Wiley, New York, 1991, pp. 115-175.

13. White, T. J., Bruns, T., Lee, S. and Taylor, J. W., Amplification and direct sequencing of fungal ribosomal RNA genes for phylogenetics. In PCR Protocols: A Guide to Methods and Applications (eds Innis, M. A. et al.), Academic Press, San Diego, 1990, vol. 64, pp. 315-322.

14. Tamura, K., Stecher, G., Peterson, D., Filipski, A. and Kumar, S., MEGA6: molecular evolutionary genetics analysis version 6.0. Mol. Biol. Evol., 2013, 30(12), 2725-2729.

15. De Nobili, M., Cercignani, G., Leita, L. and Sequi, P., Evaluation of organic matter stabilization in sewage sludge. Commun. Soi Sci. Plant Anal., 1986, 17, 1109-1119.

16. White, P., Franke, M. and Hindle, P., Integrated Solid Waste Management: A Lifecycle Inventory, Springer USA, 1995.

17. Saidi, N. et al., Evolution of Biochemical Parameters during Composting of Various Wastes Compost, Science Publications, 2008

18. Awasthi, M. K., Pandey, A. K., Khan, J., Bundela, P. S., Wong, J. W. and Selvam, A., Evaluation of thermophilic fungal consortium for organic municipal solid waste composting. Bioresour. Technol., 2014, 168, 214-221.

19. Brinton, W. F., Bonhotal, J. and Fiesinger, T., Compost sampling for nutrient and quality parameters: variability of sampler, timing and pile depth. Compost Sci. Util., 2012, 20, 141-149.

20. Reyes-Torres, M., Oviedo-Ocaña, E. R., Dominguez, I., Komilis, D. and Sánchez, A., A systematic review on the composting of green waste: feedstock quality and optimization strategies. Waste Manage., 2018, 77, 486-499.

21. Kumar, M., Ou, Y. -L. and Lin, J. -G., Co-composting of green waste and food waste at low $\mathrm{C} / \mathrm{N}$ ratio. Waste Manage., 2010, 30(4), 602-609.

22. Cabrera, M. L., Kissel, D. E. and Vigil, M. F., Nitrogen mineralization from organic residues. J. Environ. Qual., 2005, 34 75-79.

23. Barker, A. V., Composition and uses of compost. In Agricultural Uses of By-products and Wastes (eds Rechling, J. E. and Mackimon, H. C.), ACS Symposium Series (No. 668), 1997, pp. 140-162.

24. Davidson, H., Mecklenburg, R. and Peterson, C., Nursery Management: Administration and Culture (No. 635/068/ D252), Upper Saddle River, Prentice Hall, NJ, 2000.

25. Shemekite, F., Gómez-Brandón, M., Franke-Whittle, I. H., Praehauser, B., Insam, H. and Assefa, F., Coffee husk composting: an investigation of the process using molecular and non-molecular tools. Waste Manage., 2014, 34, 642-652.

26. Martins, L. F. et al., Metagenomic analysis of a tropical composting operation at the São Paulo Zoo Park reveals diversity of biomass degradation functions and organisms. PLOS ONE, 2013, 8, e61928.
27. Lavy, A., Keren, R., Yu, K., Thomas, B. C., Alvarez-Cohen, L., Banfield, J. F. and Ilan, M., A novel Chromatiales bacterium is a potential sulfide oxidizer in multiple orders of marine sponges. Environ. Microbiol., 2018, 20(2), 800-814

28. Ntougias, S., Bourtzis, K. and Tsiamis, G., The microbiology of olive mill wastes. Biomed. Res. Int., 2013, 2013, 16

29. Oie, C. S., Albaugh, C. E. and Peyton, B. M., Benzoate and salicylate degradation by Halomonas campisalis, an alkaliphilic and moderately halophilic microorganism. Water Res., 2007, 41(6), 1235-1242.

30. Young, C. C. et al., Luteimonas composti sp. nov., a moderately thermophilic bacterium isolated from food waste. Int. J. Syst. Evol. Microbiol., 2007, 57, 741-744.

31. Maeda, K., Hanajima, D., Toyoda, S., Yoshida, N., Morioka, R. and Osada, T., Microbiology of nitrogen cycle in animal manure compost. Microb. Biotechnol., 2011, 4, 700-709.

32. Takaku, H., Kodaira, S., Kimoto, A., Nashimoto, M. and Takagi, M., Microbial communities in the garbage composting with rice hull as an amendment revealed by culture-dependent andindependent approaches. J. Biosci. Bioeng., 2006, 101, 42-50.

33. Vaz-Moreira, I., Silva, M. E., Manaia, C. M. and Nunes, O. C., Diversity of bacterial isolates from commercial and homemade composts. Microb. Ecol., 2008, 55, 714-722.

34. Shivlata, L. and Satyanarayana, T., Thermophilic and alkaliphilic Actinobacteria: biology and potential applications. Front. Microbiol., 2015, 6, 1014.

35. Ishii, K., Fukui, M. and Takii, S., Microbial succession during a composting process as evaluated by denaturing gradient gel electrophoresis analysis. J. Appl. Microbiol., 2000, 89, 768777.

36. Buckley, D. H., Huangyutitham, V., Nelson, T. A., Rumberger, A. and Thies, J. E., Diversity of Planctomycetes in soil in relation to soil history and environmental heterogeneity. Appl. Environ. Microbiol., 2006, 72, 4522-4531.

37. Partanen, P., Hultman, J., Paulin, L., Auvinen, P. and Romantschuk, M., Bacterial diversity at different stages of the composting process. BMC Microbiol, 2010, 10(1), 94-105.

38. Zhai, W. et al., Arsenic methylation and its relationship to abundance and diversity of $\operatorname{ars} M$ genes in composting manure. Sci. Rep., 2017, 7, 42198.

39. Wang, C. et al., Metagenomic analysis of microbial consortia enriched from compost: new insights into the role of Actinobacteria in lignocellulose decomposition. Biotechnol. Biofuels, 2016, 9, 22.

40. Andrew, D. R., Fitak, R. R., Munguia-Vega, A., Racolta, A., Martinson, V. G. and Dontsova, K., Abiotic factors shape microbial diversity in Sonoran Desert soils. Appl. Environ. Microbiol., 2012, 78(21), 7527-7537.

41. Hugenholtz, P., Tyson, G. W., Blackall, L. L. and Björnsson, L., Filamentous Chloroflexi (green non-sulfur bacteria) are abundant in wastewater treatment processes with biological nutrient removal. Microbiology, 2015, 148, 2309-2318.

42. Antunes, L. P. et al., Microbial community structure and dynamics in thermophilic composting viewed through metagenomics and metatranscriptomics. Sci. Rep., 2016, 6, 38915-38928.

43. Carry on Composting Home and Community Composting, http://www.carryoncomposting.com/416920205.

ACKNOWLEDGEMENTS. This study was supported by the Department of Atomic Energy, Government of India in the form of fellowship to M.N.L. A major part of the metagenomic analysis was carried out at M/s APS Lifetech, Pune, India.

Received 24 April 2019; revised accepted 22 August 2019

doi: $10.18520 / \mathrm{cs} / \mathrm{v} 117 / \mathrm{i} 11 / 1842-1854$ 